\title{
Predictors of Hepatitis Knowledge Improvement Among Methadone Maintained Clients Enrolled in a Hepatitis Intervention Program
}

\author{
Adeline Nyamathi $\cdot$ Darlene Tyler $\cdot$ Karabi Sinha $\cdot$ \\ Mary Marfisee $\cdot$ Allan Cohen $\cdot$ Barbara Greengold
}

Published online: 1 April 2010

(C) The Author(s) 2010. This article is published with open access at Springerlink.com

\begin{abstract}
This randomized, controlled study $(n=256)$ was conducted to compare three interventions designed to promote hepatitis A virus (HAV) and hepatitis B virus (HBV) vaccination completion, among clients undergoing methadone maintenance treatment (MMT) in Los Angeles and Santa Monica. The participants were randomized into three groups: Motivational Interviewing-Single Session (MI-Single), Motivational Interviewing-Group (MIGroup), or Nurse-Led Hepatitis Health Promotion (HHP). All three treatment groups received the 3-series HAV/HBV vaccine. The MI sessions were provided by trained therapists, the Nurse-Led HHP sessions were delivered by a research nurse. The main outcome variable of interest was improvement in HBV and HCV knowledge, measured by a 6-item HBV and a 7-item HCV knowledge and attitude tool that was administered at baseline and at 6-month follow-up. The study results showed that there was a significant increase in HBV- and HCV-related knowledge across all three groups $(p<0.0001)$. There were no significant differences found with respect to knowledge acquisition among the groups. Irrespective of treatment group, gender $(P=0.008)$, study site $(P<0.0001)$ and whether a participant was abused as a child $(P=0.017)$ were all found to be predictors of $\mathrm{HCV}$ knowledge improvement; only recruitment site $(P<0.0001)$ was found to be a predictor of HBV knowledge. The authors concluded that, although
\end{abstract}

\footnotetext{
A. Nyamathi $(\bowtie) \cdot$ D. Tyler $\cdot$ K. Sinha $\cdot$ M. Marfisee .

B. Greengold

UCLA, School of Nursing, 700 Tiverton Avenue,

Los Angeles, CA 90095-1702, USA

e-mail: anyamath@sonnet.ucla.edu

A. Cohen

Bay Area Addiction, Research and Treatment Inc.,

1926 W. Beverly Blvd., Los Angeles, CA 90057, USA
}

MI-Single, MI-Group and Nurse-Led HHP are all effective in promoting $\mathrm{HBV}$ and $\mathrm{HCV}$ knowledge acquisition among MMT clients, Nurse-Led HHP may be the method of choice for this population as it may be easier to integrate and with additional investigation may prove to be more cost efficient.

Keywords Hepatitis knowledge .

Methadone maintenance $\cdot$ Nursing intervention

\section{Introduction}

High rates of viral hepatitis have been reported in heroin users receiving methadone maintenance therapy (MMT). Early epidemiological studies of MMT in the United States (U.S.) and internationally have revealed that $85-95 \%$ of MMT individuals have at least one marker for $\mathrm{HBV}$ infection, while $60-98 \%$ are anti-HCV positive [1-6]. Although MMT programs reduce and often eliminate heroin injection drug use, individuals who experience gaps in treatment or continue with injection use remain at risk for acquiring hepatitis virus infections [7].

MMT programs are more likely than drug free programs to provide participants with information about HBV and HCV transmission and the importance of hepatitis A and B vaccination $[8,9]$. In a nationwide sample of 595 drug treatment programs, 407 drug free programs and 188 MMT programs, findings revealed that MMT programs provided HCV education to about $75 \%$ of all patients, while drug free programs provided $\mathrm{HCV}$ education to $50 \%$ of patients [9]. Nevertheless, there is a paucity of research exists on the HBV and HCV knowledge level of patients who frequent MMT. Determining the knowledge level of HBV and $\mathrm{HCV}$ among MMT participants is necessary for evaluating 
the effectiveness of such programs which exist in MMTs and which aim to decrease the acquisition and spread of HBV and HCV infections among MMT participants and their partners. To date, there have been no studies assessing predictors of knowledge improvement among this population. The purpose of this study is to evaluate the efficacy of one of three delivery approaches in enhancing knowledge of HCV and HBV among a sample of MMT participants.

\section{Knowledge of Hepatitis Among MMT Participants}

There is sparse research regarding knowledge of hepatitis among individuals receiving MMT. Currently, two studies evaluating HCV knowledge have been reported in the literature. In surveying MMT participants in San Francisco, Walley, White, Kushel, Song and Tulsky [10] found that while most participants believed HCV to be a fatal disease and understood how HCV was transmitted, many were unaware that treatment was available. In a second study of 306 IDUs receiving MMT, most knew that HCV was transmitted by sharing needles, and $77 \%$ believed $\mathrm{HCV}$ could be transmitted sexually. However, only $70 \%$ knew that condoms were protective [11].

\section{Predictors of Hepatitis Knowledge}

One study has assessed predictors of hepatitis knowledge in MMT participants. Knowledge of HCV was assessed among participants accessing an opiate dependence treatment program in San Francisco [10]. These authors found no significant differences in HCV knowledge between race and gender; however, being male, White, HCV positive and more highly educated was associated with higher knowledge level of $\mathrm{HCV}$ treatment. Among the general adult population of community dwelling Australian adults, predictors of HCV knowledge included younger age (2049), higher education level, higher occupation level, previous diagnosis with a sexually transmitted infection, and for women, higher income [12]. We believe we are the first to assess predictors of improvement in $\mathrm{HBV}$ and $\mathrm{HCV}$ knowledge among MMT clients enrolled in one of three education delivery models: Motivational Interviewing, delivered one-on one (MI-Single), MI- group or Nurse-led Hepatitis Health Promotion (HHP).

\section{Motivational Interviewing}

Motivational interviewing (MI) is a non-confrontational process designed to improve willingness to consider behavior change [13]. Although MI has been applied to various areas of health behavior change, including obesity, HIV risk factor modification and eating disorders, the broadest application of this approach has been in the area of addiction [14]. MI involves a partnership between provider and client which provides for tailored interventions to suite the client's degree of readiness for change and allows providers' an effective means of working with clients who are ambivalent about or not ready for change [15]. Studies have shown that MI is effective for the reduction of substance abuse among people with a history of chemical dependence [16], whether delivered on a one-to-one basis [17] or as group therapy $[18,19]$. Velasquez and colleagues [20] showed that MI delivered individually and in a group setting was effective in reducing alcohol abuse and risky sexual behavior among a sample of men who have sex with other men.

\section{Nurse-Led Interventions}

One of the key roles of the nurse is to promote health [21], and as such nurses are ideally suited to deliver brief interventions. A number of studies have demonstrated that nurse-led interventions seeking to reduce alcohol among substance users have been effective [22-24]. Nurse-led studies have also revealed significant decrease in alcohol scores among postpartum women with alcohol problems [23]. Nurse-led programs have likewise resulted in decrease in drug use $[25,26]$. These findings highlight the fact that nurse-led interventions have high potential for reducing substance use among at-risk populations and would be worthy of testing in a methadone-maintained population as well.

\section{Method}

The study design was a randomized controlled trial of 256 moderate and heavy alcohol-using adults receiving MMT in Los Angeles and who were randomized to one of three treatment groups; the MI-Single, MI-Group or Nurse-led HHP. This randomization occurred upon completion of a structured baseline questionnaire by trained research staff. The participants in each of the groups received three timeequivalent sessions over a 6 week period. The MI sessions were delivered by two trained therapists specialized in delivering MI. The Nurse-HP sessions were delivered by a research nurse in conjunction with a trained research staff member. The HAV/HBV vaccination series was provided to all participants found to be HBV seronegative free of charge. Baseline data were collected from February 2007 to May 2008. Follow-up data were collected 6 months post baseline.

Sample and Setting

Eligibility criteria for the MMT clients included: (a) having received methadone for at least 3 months; (b) 18-55 years 
of age; and (c) reported moderate-to-heavy alcohol use based on questions from the Addiction Severity Index (ASI). Participants were recruited from five MMT sites in the Los Angeles and Santa Monica areas for which permission was obtained from the site directors. These sites included: Bay Area Addiction (BAART) clinics in the areas of Beverly, Southeast, and Lynwood, and non-BAART MMT sites in Santa Monica (Matrix) and Southeast Los Angeles (TriCity).

\section{Procedure}

Participants were recruited from each of the sites by means of posted flyers. Among all interested individuals, after more detailed information was provided about the screener, informed consent for undergoing a brief screening was read and signed in a private room at each site. Subsequently, research staff administered the 2-min structured questionnaire composed of socio-demographic characteristics, a screen for alcohol use and severity, and a hepatitis-related health history.

Among persons who met eligibility criteria, detailed information was provided about the study, and if interest continued, a second-level consent for blood testing was requested. Eligible clients who wished to participate further completed a third consent form prior to enrollment into the study. The study and associated materials were approved by the Human Subject Protection Committee.

\section{Measures}

A structured questionnaire captured data on age, gender, birthdate, ethnicity, education, history of childhood physical abuse, history of substance abuse treatment, recruitment site, and history of trading sex lifetime.

Perceived Health Status was measured on a 5-point scale from "excellent" to "poor"; with health status dichotomized at fair/poor versus better health.

Drug use was measured by the Addiction Severity Index-Lite Version. This measure is a shortened version of the ASI 5th edition [27]. Drug use was dichotomized at its median for clarity of presentation in this study. Alcohol use was assessed by the Time Line Follow Back that assessed the number of standard drinks consumed per day over the last 30 days.

Social Support was measured by a 9-item scale used in the RAND Medical Outcomes Study [28]. The items elicited information about how often respondents had friends, family or partners available to provide them with food, a place to stay, etc., on a five-point Likert scale. The instrument has demonstrated high convergent and discriminant validity; internal consistency reliability coefficients range from 0.91 to 0.97 for the subscales [28].
Cronbach's alpha for the scale in this study was .94. An additional question inquired about whether social support came primarily from drug users, non-drug users or both.

Depressive Symptoms were assessed with the Center for Epidemiological Studies Depression (CES-D) scale [29] and has been validated for use in homeless populations.

MHI-5, a five-tem mental health index, is a measure of emotional well-being and has well-established reliability and validity [30] An established cut point of 66 [31] was used to identify participants' emotional well-being.

\section{Statistical Data Analyses}

All analyses were intent-to-treat. The outcome variables of interest were improvement in $\mathrm{HBV}$ and $\mathrm{HCV}$ knowledge. $\mathrm{HBV}$ and HCV knowledge were measured by a participant's total score on the 6-item $\mathrm{HBV}$ and 7-item HCV "Knowledge and Attitudes towards Hepatitis" tools. Participants were administered these knowledge tools at both baseline and 6-month follow-up. An improvement in knowledge is observed when the total knowledge score at 6 months' follow-up is greater than that measured at baseline. The average improvement in knowledge was documented in the sample as a whole as well as by different program types and demographic and behavioral characteristics. $T$-tests and analysis of variance methods were used to assess differences in the outcome measures by different groups. General linear models were built to find best predictors of improvement in knowledge. Tests for multicollinearity were conducted and goodness of model fit was checked. Since participants' knowledge in HBV and HCV are likely to be correlated, a multivariate analysis was conducted to find best predictors of the improvement in both knowledge variables, accounting for correlation between these knowledge types. All necessary assumptions were checked and met. All statistical analyses were performed with SAS/STAT.

\section{Results}

\section{Sociodemographic Characteristics}

Compilation of the sample is as described in Table 1. A total of 256 MMT participants were randomized into the MI-S ( $n=90)$, MI-G $(n=79)$ or Nurse-led HHP $(n=87)$ group. A few participants $(n=6)$ reported no alcohol use in the past month at baseline. As shown on Table 1, more than half the sample $(59 \%)$ was male and predominantly African American (45\%) or Latino (27\%). The mean age of the sample was 51 years $(\mathrm{SE}=0.83)$. Slightly more than half of the participants completed high school, and reported having a significant other. About one-third of participants 
Table 1 Baseline sample characteristics of methadone maintained clients by program

\begin{tabular}{|c|c|c|c|c|}
\hline & $\begin{array}{l}\text { MI-single } \\
(N=90)\end{array}$ & $\begin{array}{l}\text { MI-group } \\
(N=79)\end{array}$ & $\begin{array}{l}\mathrm{HP} \\
(N=87)\end{array}$ & $\begin{array}{l}\text { Total } \\
(N=256)\end{array}$ \\
\hline \multicolumn{5}{|l|}{ Background } \\
\hline Mean age (SE) & $51.9(0.83)$ & $50.0(0.83)$ & $51.8(0.94)$ & $51.2(0.53)$ \\
\hline Male $(\%)$ & 60.0 & 58.2 & 59.3 & 59.2 \\
\hline \multicolumn{5}{|l|}{ Ethnicity (\%) } \\
\hline African American & 46.7 & 44.3 & 44.2 & 45.1 \\
\hline White & 21.1 & 24.1 & 11.6 & 18.8 \\
\hline Latino & 25.6 & 25.3 & 29.1 & 26.7 \\
\hline Other & 6.7 & 6.3 & 15.1 & 9.4 \\
\hline High school grad (\%) & 62.2 & 59.5 & 52.3 & 58.0 \\
\hline Partnered $(\%)$ & 51.7 & 55.7 & 55.8 & 54.3 \\
\hline Employed (\%) & 18.0 & 12.7 & 20.9 & 17.3 \\
\hline \multicolumn{5}{|l|}{ Recruitment site (\%) } \\
\hline Beverly & 16.9 & 21.8 & 23.8 & 20.7 \\
\hline Southeast & 31.5 & 37.2 & 28.6 & 32.3 \\
\hline Lynwood & 9.0 & 9.0 & 8.3 & 8.8 \\
\hline Matrix & 28.0 & 23.1 & 23.8 & 24.7 \\
\hline TriCity & 15.7 & 9.0 & 15.7 & 13.6 \\
\hline Fair/poor health & 58.9 & 63.3 & 59.3 & 60.4 \\
\hline Childhood physical abuse & 23.3 & 27.9 & 24.4 & 25.1 \\
\hline Lifetime trade sex & 31.8 & 46.7 & 32.9 & 36.7 \\
\hline \multicolumn{5}{|l|}{ Substance use } \\
\hline \multicolumn{5}{|l|}{ Recent $^{+}$alcohol use at baseline $(\%)$} \\
\hline $0-40$ & 23.3 & 27.9 & 24.4 & 25.1 \\
\hline $41-89$ & 21.1 & 22.8 & 30.2 & 24.7 \\
\hline $90-180$ & 32.2 & 22.8 & 24.4 & 26.7 \\
\hline$>180$ & 23.3 & 26.6 & 20.9 & 23.5 \\
\hline Recent $^{+}$marijuana use $(\%)$ & 17.8 & 25.3 & 5.8 & 16.0 \\
\hline Recent $^{+}$IDU (\%) & 37.8 & 45.6 & 37.2 & 40.0 \\
\hline Smoke $\geq 1$ pack/day $(\%)$ & 52.2 & 64.6 & 52.3 & 56.1 \\
\hline Recent $^{+}$self-help program $(\%)$ & 23.3 & 25.3 & 15.1 & 21.2 \\
\hline $\begin{array}{l}>50 \% \text { reduction in alcohol use } \\
\text { at } 6 \text { months }(\%)\end{array}$ & 46.6 & 54.0 & 49.4 & 49.8 \\
\hline \multirow{2}{*}{$\begin{array}{l}\text { No recent }{ }^{+} \text {alcohol use } \\
\text { at } 6 \text { months }(\%)\end{array}$} & 22.2 & 20.3 & 23.3 & 22.0 \\
\hline & $\begin{array}{l}\text { MI-single } \\
(N=88)\end{array}$ & $\begin{array}{l}\text { MI-group } \\
(N=76)\end{array}$ & $\begin{array}{l}\mathrm{HP} \\
(N=85)\end{array}$ & $\begin{array}{l}\text { Total } \\
(N=249)\end{array}$ \\
\hline \multicolumn{5}{|l|}{ Psychological resources } \\
\hline Depressive $\operatorname{Sxs}^{\mathrm{a}}(\%)$ & 81.1 & 81.1 & 80.2 & 80.8 \\
\hline Poor emotional well being ${ }^{\mathrm{b}}(\%)$ & 73.3 & 65.8 & 62.8 & 67.5 \\
\hline \multicolumn{5}{|l|}{ Social support from (\%) } \\
\hline Primarily drug users & 7.8 & 12.7 & 17.4 & 12.6 \\
\hline Primarily non drug users & 51.1 & 45.6 & 48.8 & 48.6 \\
\hline Both & 34.4 & 38.0 & 32.6 & 34.9 \\
\hline No one & 6.7 & 3.8 & 1.2 & 3.9 \\
\hline
\end{tabular}

+ Recent refers to past month

${ }^{a}$ Based on a CES-D short form (10 items) score of 8 or more

b Based on a score of 65 or less on a $0-100$ scale 
received social support from both drug-users and non-drug users, while almost half reported social support from primarily non drug users. A total of $87 \%$ of participants completed all three sessions and $91 \%$ completed the 6 month follow-up.

Improvement in HCV and HBV Knowledge by Demographic Characteristics

Associations between knowledge outcome measures and sample characteristics are depicted in Table 2. Overall, knowledge of both HCV and HBV increased significantly from pretest to posttest $(P<.0001)$. While BAART Beverly participants reported the highest baseline knowledge scores $(X=19.21$, SD 0.48) compared to the other sites, improvement in posttest scores in BAART Southeast and Matrix were significantly greater $(X=22.57$, SD .26 and $X=22.32$, SD .24) compared to BAART Beverly posttest scores $(X=19.56, \mathrm{SD} .28)$. These patterns were similar for $\mathrm{HCV}$.

Significant differences in HCV knowledge improvement were observed by gender, race, whether a person was physically abused as a child or not and being a heavy smoker versus not. Men showed a greater improvement in $\mathrm{HCV}$ knowledge at 6 months than women. African Americans showed a greater improvement in $\mathrm{HCV}$ knowledge while Caucasians showed the least. Those that were physically abused as children showed lesser improvement in knowledge than their non-abused counterparts. Also light smokers showed greater HCV knowledge improvement than heavy smokers. Additionally, type of site and kinds of support were significantly different for both HBV and HCV knowledge improvements.

As for support, those that had non-drug-alcohol users as their primary support showed greater improvement in knowledge in both measures. Participants who self reported not using marijuana in the last 6 months performed better on HBV and HCV knowledge than their marijuana-using counterparts.

\section{Regression Predictors for HCV Knowledge \\ Improvement}

Table 3a shows the result from a generalized linear model for improvement in HCV Knowledge. A stepwise linear regression analysis was used to identify predictors for knowledge improvement; predictors included variables that were associated with improvement in knowledge at the 0.15 level in preliminary analyses. Indicators for MI-single and MI-group assignment were included in all models; other covariates were retained in the generalized linear model if they were significant at the .10 level. There were no significant differences in knowledge improvement across program types, i.e., all three programs led to comparable improvement in knowledge at 6 months. Gender $(P=0.008)$, site $(P<0.0001)$, and whether a participant was abused as a child $(P=0.017)$ continued to have significant effect on the outcome (as evidenced in the univariate analyses in Table 2) and were retained in the multiple regression model as significant predictors. Race however was no longer a significant predictor $(P$-value $=0.38)$.

Regression Predictors for HBV Knowledge Improvement

A generalized linear model was similarly fit to model improvement in HBV knowledge (see Table 3b). Only recruitment site continued to be a significant predictor for knowledge improvement $(P$-value $<0.0001)$ in the multiple regression model.

\section{Multivariate Analysis}

Considering the strong significant correlation between knowledge improvement in $\mathrm{HBV}$ and $\mathrm{HCV}(r=0.49$, $P$-value $<0.0001)$, we considered fitting a multivariate model for HBV and HCV to explore simultaneous predictors of improvement in both kinds of knowledge. We used PROC MIXED in SAS with compound symmetry variance-covariance structure (which takes the correlation between HBV and HCV into account and further assumes that their individual variances are approximately equal, which in this case, they are). The benefit of this kind of modeling is that it enhances the likelihood of identifying significant predictors for both outcomes that otherwise may not be significant in univariate models. This likelihood is due to the increased power of multivariate models over univariate ones. Table 4 shows the result from the multivariate analysis. We see that gender $(P$-value $=0.01)$, recruitment site $(P$-value $<0.0001)$ and childhood abuse $(P$-value $=0.03)$ are now all significant predictors of both knowledge.

\section{Discussion}

This research focused on predictors of improvement in HBV and HCV knowledge among moderate and heavy alcohol-using adults receiving MMT. The three interventions (MI-Individual, MI-Group, or Nurse-Led HHP) each provided information about $\mathrm{HBV}$ and $\mathrm{HCV}$ and the effects of continued alcohol use on the liver. MI-trained therapists provided either one-on-one or group MI; nurses delivered 
Table 2 Assessing improvements in HBV and HCV knowledge by demographic and behavioral characteristics of methadone maintained clients

\begin{tabular}{|c|c|c|}
\hline & $\begin{array}{l}\text { Improvement in HBV } \\
\text { knowledge mean (SE) }\end{array}$ & $\begin{array}{l}\text { Improvement in } \mathrm{HCV} \\
\text { knowledge mean (SE) }\end{array}$ \\
\hline \multicolumn{3}{|l|}{ Program type } \\
\hline MI-S & $3.08(0.36)$ & $3.78(0.42)$ \\
\hline MI-G & $2.62(0.44)$ & $4.17(0.36)$ \\
\hline UC & $3.33(0.42)$ & $4.24(0.42)^{*}$ \\
\hline \multicolumn{3}{|l|}{ Gender } \\
\hline Male & $2.85(0.30)$ & $4.44(0.32)$ \\
\hline Female & $3.21(0.38)$ & $3.47(0.34)^{*}$ \\
\hline \multicolumn{3}{|l|}{ Race } \\
\hline African American & $3.33(0.32)$ & $4.78(0.32)$ \\
\hline White & $1.77(0.61)$ & $2.79(0.50)$ \\
\hline Latino & $3.19(0.40)$ & $3.71(0.43)$ \\
\hline Other & $3.79(1.59)$ & $3.83(1.42)$ \\
\hline \multicolumn{3}{|l|}{ High school grad } \\
\hline Yes & $3.11(0.31)$ & $4.08(0.32)$ \\
\hline No & $2.86(0.36)$ & $3.99(0.35)$ \\
\hline \multicolumn{3}{|l|}{ Employed } \\
\hline Yes & $3.33(0.64)$ & $4.52(0.59)$ \\
\hline No & $2.92(0.25)^{+}$ & $3.93(0.26)^{*}$ \\
\hline \multicolumn{3}{|l|}{ Recruitment site } \\
\hline Beverly & $0.36(0.53)$ & $0.92(0.51)$ \\
\hline Southeast & $4.36(0.36)$ & $5.19(0.37)$ \\
\hline Lynwood & $1.73(0.65)$ & $4.60(0.64)$ \\
\hline Matrix & $3.55(0.43)$ & $4.75(0.38)$ \\
\hline TriCity(other) & $3.47(0.54)$ & $4.11(0.65)$ \\
\hline \multicolumn{3}{|l|}{ Fair health } \\
\hline Yes & $2.88(0.56)$ & $4.03(0.38)$ \\
\hline No & $3.21(0.36)$ & $4.05(0.30)^{* * *}$ \\
\hline \multicolumn{3}{|c|}{ Childhood physical abuse } \\
\hline Yes & $2.53(0.50)$ & $2.87(0.50)$ \\
\hline No & $3.16(0.26)$ & $4.44(0.26)$ \\
\hline \multicolumn{3}{|l|}{ Lifetime trade sex } \\
\hline Yes & $3.04(0.39)$ & $3.72(0.38)$ \\
\hline No & $2.98(0.29)$ & $4.24(0.30)$ \\
\hline \multicolumn{3}{|l|}{ Substance use } \\
\hline \multicolumn{3}{|c|}{ Recent alcohol use at baseline } \\
\hline $0-40$ & $3.18(0.44)$ & $3.64(0.49)$ \\
\hline $41-89$ & $3.22(0.44)$ & $4.30(0.51)$ \\
\hline $90-180$ & $2.84(0.48)$ & $4.22(0.47)$ \\
\hline$>180$ & $2.77(0.52)$ & $4.05(0.39)$ \\
\hline \multicolumn{3}{|c|}{ Recent marijuana use at baseline } \\
\hline Yes & $3.00(0.56)$ & $4.29(0.55)$ \\
\hline No & $3.00(0.26)$ & $3.99(0.26)$ \\
\hline \multicolumn{3}{|c|}{ Recent IDU at baseline } \\
\hline Yes & $2.62(0.34)$ & $3.56(0.35)$ \\
\hline No & $3.24(0.31)$ & $4.34(0.31)^{*}$ \\
\hline \multicolumn{3}{|l|}{ Smoke $>1 \mathrm{pack} /$ day } \\
\hline Yes & $2.99(0.45)$ & $3.54(0.36)$ \\
\hline No & $3.01(0.27)$ & $4.25(0.29)$ \\
\hline
\end{tabular}


Table 2 continued

* Significant difference in $\mathrm{HCV}$ knowledge improvement,

$P$-value $<0.05$

*** Significant difference in HCV knowledge improvement, $P$-value $<0.005$

+ Significant difference in HBV knowledge improvement,

$P$-value $<0.05$

++ Significant difference in HBV knowledge improvement, $P$-value $<0.005$

+++ Significant difference in HBV knowledge improvement, $P$-value $<0.005$

\begin{tabular}{lll}
\hline & $\begin{array}{l}\text { Improvement in HBV } \\
\text { knowledge mean (SE) }\end{array}$ & $\begin{array}{l}\text { Improvement in HCV } \\
\text { knowledge mean (SE) }\end{array}$ \\
\hline $\begin{array}{l}\text { Recent self-help program } \\
\text { Yes }\end{array}$ & $2.91(0.57)$ & $4.16(0.65)$ \\
No & $3.01(0.26)^{+++}$ & $4.02(0.26)^{*}$ \\
Social support & $1.26(0.88)$ & $3.71(0.77)$ \\
No one & $1.19(0.71)$ & $2.29(0.54)$ \\
Primarily drug/alcohol users & $3.69(0.33)$ & $4.53(0.35)$ \\
Primarily non-drug & $3.02(0.38)$ & $4.02(0.41)$ \\
Equally divided & & $3.88(0.35)$ \\
Recent alcohol use at 6 mo & $3.40(0.34)$ & $3.61(0.55)$ \\
$0-40$ & $2.20(0.50)$ & $4.81(0.52)$ \\
$41-89$ & $2.99(0.59)$ & $4.14(0.58)$ \\
$90-180$ & $2.74(0.56)^{++}$ & \\
$>180$ & & $3.94(0.96)$ \\
Recent marijuana use at 6 mo & $1.86(0.81)$ & $4.05(0.24)$ \\
Yes & $3.10(0.24)$ & \\
No & & \\
\hline
\end{tabular}

Table 3 Regression predictors for methadone-maintained adults showing improvement in (a) HCV knowledge $(n=222)$, (b) HBV knowledge $(n=223)$

\begin{tabular}{lccrrc}
\hline Predictor & DF & Type III SS & Mean SS & $F$-value & $P$-value \\
\hline (a) HCV knowledge & $(n=222)$ & & & \\
Program type & 2 & 22.22 & 11.11 & 1.17 & 0.310 \\
Sex** & 1 & 69.14 & 69.14 & 7.28 & 0.008 \\
Race & 3 & 29.06 & 9.69 & 1.02 & 0.380 \\
Recruitment site*** & 4 & 489.32 & 122.33 & 12.88 & $<0.0001$ \\
Abused as a child* & 1 & 55.32 & 55.32 & 5.83 & 0.017 \\
(b) Knowledge $(n=223)$ & & & & \\
Program type & 2 & 22.35 & 11.17 & 1.06 & 0.35 \\
Recruitment site*** & 4 & 459.62 & 114.90 & 10.87 & $<0.0001$ \\
Social support & 3 & 63.20 & 21.07 & 1.99 & 0.12 \\
$\quad$ at 6 mo & & & & & \\
\hline
\end{tabular}

the Nurse-Led HHP. Findings revealed that knowledge of $\mathrm{HBV}$ and $\mathrm{HCV}$ improved significantly from pretest to posttest for all three delivery formats.

Our findings that MI effectively promotes hepatitis knowledge are consistent with findings from other studies showing that this mode of therapy promotes treatment adherence, and HIV risk reduction [32]. Moreover, our study also adds to the growing body of evidence that nurseled educational interventions are likewise effective. Wolfers and colleagues [33] showed that nurse-delivered counseling resulted in a reduction of risky sexual behaviors among gay and bisexual men receiving HBV vaccination. Nyamathi and colleagues [34] demonstrated that a nurseled intervention which included an educational component
Table 4 Multivariate Regression showing predictors for methadonemaintained adults showing improvement in HBV and HCV knowledge $(n=222)$

\begin{tabular}{lcc}
\hline Predictor & Wilks' lambda & $P$-value \\
\hline Program type & 0.98 & 0.39 \\
Gender* & 0.96 & 0.01 \\
Recruitment site*** & 0.72 & $<0.0001$ \\
Abused as a child* & 0.97 & 0.03 \\
\hline * Significant effect, $P$-value $<0.05$ & \\
$* *$ Significant effect, $P$-value $<0.005$ & \\
$* * *$ Significant effect, $P$-value $<0.005$ &
\end{tabular}

was associated with enhanced HBV vaccination compliance, among homeless adults. Nevertheless, we found no significant differences with respect to knowledge acquisition among the groups. Our findings provide new evidence that a nurse-led intervention can be as effective as MI with regard to hepatitis knowledge acquisition. Ongoing investigations are needed to assess cost effectiveness of nurseled HHP programs as compared to therapist-trained MI sessions. The incorporation of nurses can have a dual impact of providing counseling as well as health care delivery and may consequently be more appealing for the MMT population who experience numerous health-related problems [35].

Results also showed that significant differences in study outcomes were associated with variability in clinical sites. The BAART Southeast and Matrix clinic revealed the lowest baseline scores but achieved the greatest improvement in knowledge scores of both $\mathrm{HBV}$ and $\mathrm{HCV}$. 
Campbell and colleagues [36] showed that HBV vaccination completion rates varied depending on the state of residence among young IDUs; Linton and colleagues [37] reported significantly different vaccination completion rates, comparing private to public school students. We suspect that the significant improvement in HBV and HCV knowledge among participants from the BAART Southeast and Matrix clinic may reflect the very low base level of knowledge existing within this population and the need for more available and more intensive hepatitis education for this high-risk population. In contrast, those from the BAART Beverly site may have previously received hepatitis education, so their increase in hepatitis knowledge was minimal.

We found that males had a significantly greater improvement in HCV knowledge compared with females. This may have been related to the fact that males may have perceived themselves to be at higher risk for hepatitis because, in the United States, the rates of Hepatitis B continue to be high especially among males aged 30-44 [38]. Women, though, may have perceived their risk for hepatitis differently than men. Women participating in short term drug treatment felt themselves to be at low risk for hepatitis infection despite previous high-risk behaviors; instead they were more concerned about contracting sexually transmitted infections [39].

As shown in our results, the type of social support received by participants was a determinant in the amount of HCV knowledge improvement demonstrated. A gender difference by support type may have existed. Greater improvement in HCV knowledge occurred among those with non-drug using sex partners. Kidorf and colleagues [40] reported that positive social support is associated with positive outcomes among opioiddependent patients.

We also found that individuals with a history of childhood sexual abuse demonstrated less knowledge improvement, compared with those without such a history. It has been shown that childhood sexual abuse acts as a psychological barrier to practicing harm reduction strategies for hepatitis and human immunodeficiency virus [41]. Individuals, especially women, with a history of childhood sexual abuse may face continued issues of fear of anger, violence, coercion, and abandonment that may perpetuate high-risk behaviors and interfere with receipt of hepatitis education [42, 43]. As a result, it remains important to provide hepatitis education to these individuals, as they remain at risk for acquiring hepatitis.

There are some limitations which must be considered when interpreting the results of our study. The study was carried out across six different treatment sites which may limit the generalizability of our findings, especially since an association was found between study site and outcome.

\section{Conclusion}

Illicit drug users have cited lack of information and knowledge about $\mathrm{HCV}$ as a barrier to hepatitis infection treatment [44]. Lack of disease-specific knowledge has been identified as a key barrier for hepatitis testing and vaccination, among injection drug using women [39]. We have attempted to address these needs by measuring the effects of three programs designed to enhance HBV- and HCV-related knowledge among participants attending MMT. We were able to demonstrate that MI-single, MIgroup and nurse-led HHP resulted in knowledge improvement. We found that clinical study site, employment status, being male, and having a positive social support system were predictors of hepatitis knowledge (that is, they were associated with greater knowledge improvement). Our most salient finding was that the nurse-led HHP group did as well as the non-nurse MI groups with respect to knowledge acquisition, which leads us to believe that further studies may show Nurse-Led HHP to be the strategy of choice in this population.

Open Access This article is distributed under the terms of the Creative Commons Attribution Noncommercial License which permits any noncommercial use, distribution, and reproduction in any medium, provided the original author(s) and source are credited.

\section{References}

1. Bart, G., Piccolo, P., Zhang, L., Jacobson, I., Schaefer, R. A., \& Kreek, M. J. (2008). Markers for hepatitis A, B and C in methadone maintained patients: An unexpectedly high co-infection with silent hepatitis B. Addiction, 103(4), 681-686.

2. Best, D., Noble, A., Finch, E., Gossop, M., Sidwell, C., \& Strang, J. (1999). Accuracy of perceptions of hepatitis B and C status: Cross sectional investigation of opiate addicts in treatment. British Medical Journal, 319(7205), 290-291.

3. Dhopesh, V. P., Taylor, K. R., \& Burke, W. M. (2000). Survey of hepatitis $\mathrm{B}$ and $\mathrm{C}$ in addiction treatment unit. American Journal of Drug and Alcohol Abuse, 26(4), 703-707.

4. McCarthy, J. J., \& Flynn, N. (2001). Hepatitis C in methadone maintenance patients: Prevalence and public policy implications. Journal of Addictive Disease, 20(1), 19-31.

5. Murrill, C. S., Weeks, H., Castrucci, B. C., Weinstock, H. S., Bell, B. P., Spruill, C., et al. (2002). Age-specific seroprevalence of HIV, hepatitis B virus, and hepatitis $\mathrm{C}$ virus infection among injection drug users admitted to drug treatment in six US cities. American Journal of Public Health, 92(3), 385-387.

6. Piccolo, P., Borg, L., Lin, A., Melia, D., Ho, A., \& Kreek, M. J. (2002). Hepatitis C virus and human immunodeficiency virus-1 co-infection in former heroin addicts in methadone maintenance treatment. Journal of Addictive Diseases, 21(4), 55-66.

7. Crofts, N., Nigro, L., Oman, K., Stevenson, E., \& Sherman, J. (1997). Methadone maintenance and hepatitis C virus infection among injecting drug users. Addiction, 92(8), 999-1005.

8. Strauss, S. M., Astone, J. M., Hagan, H., \& Des Jarlais, D. C. (2004). The content and comprehensiveness of hepatitis $C$ education in methadone maintenance and drug-free treatment units. Journal of Urban Health, 81(1), 38-47. 
9. Strauss, S. M., Astone, J., Vassilev, Z. P., Des Jaralis, D. C., \& Hagan, H. (2003). Gaps in the drug-free and methadone treatment program response to Hepatitis C. Journal of Substance Abuse Treatment, 24(4), 291-297.

10. Walley, A. Y., White, M. C., Kushel, M. B., Song, Y. S., \& Tulsky, J. P. (2005). Knowledge of and interest in hepatitis C treatment at a methadone clinic. Journal of Substance Abuse Treatment, 28(2), 181-187.

11. Stein, M. D., Maksad, J., \& Clarke, J. (2001). Hepatitis C disease among injection drug users: Knowledge, perceived risk and willingness to receive treatment. Drug and Alcohol Dependence, 61(3), 211-215.

12. Grulich, A. E., de Visser, R. O., Smith, A. M. A., Rissel, C. E., \& Richters, J. (2003). Knowledge about sexually transmitted infections and blood-borne viruses in a representative sample of adults. Australian and New Zealand Journal of Public Health, 27(2), 230-233.

13. Rapp, R. C., Otto, A. L., Lane, D. T., Redko, C., McGatha, S., \& Carlson, R. (2008). Improving linkage with substance abuse treatment using brief case management and motivational interviewing. Drug and Alcohol Dependence, 94(1-3), 172182.

14. Ogedegbe, G., Schoenthaler, A., Richardson, T., Lewis, L., Belue, R., Espinosa, E., et al. (2006). An RCT of the effect of motivational interviewing on medication adherence in hypertensive African Americans: Rationale and design. Contemporary Clinical Trials, 28(2), 169-181.

15. Britt, E., Hudson, S. M., \& Blampied, N. M. (2004). Motivational interviewing in health settings: A review. Patient Education \& Counseling, 53(2), 147-155.

16. Bradley, A. C., Baker, A., \& Lewin, T. J. (2007). Group intervention for coexisting psychosis and substance use disorders in rural Australia: Outcomes over 3 years. Australian \& New Zealand Journal of Psychology, 14(6), 501-508.

17. Carey, K. B., Scott-Sheldon, L. A., Carey, M. P., \& DeMartini, K. S. (2007). Individual-level interventions to reduce college student drinking: A meta-analytic review. Addictive Behaviors, 32(11), 2469-2494.

18. LaBrie, J. W., Thompson, A. D., Huchting, K., Lac, A., \& Buckley, K. (2007). A group motivational interviewing intervention reduces drinking and alcohol related negative consequences in adjudicated college women. Addictive Behaviors, 32, 2549-2562.

19. Santa Ana, E., \& Wulfert, E. (2007). Efficacy of group motivational interviewing (GMI) for psychiatric inpatients with chemical dependence. Clinical Psychology, 75, 816-822.

20. Velasquez, M. M., von Sternberg, K., Carbonari, J. P., Green, C., \& Parsons, J. T. (2009). Reducing sexual risk behaviors and alcohol use among HIV-positive men who have sex with men: A randomized clinical trial. Journal of Consulting and Clinical Psychology, 77(4), 657-667.

21. Lock, C., Kaner, E., Heather, N., Doughty, J., Crenshaw, A., \& McNamee, P. (2006). Effectiveness of nurse-led brief alcohol intervention: A cluster randomized controlled trial. Journal of Advanced Nursing, 54(4), 426-439.

22. Cummings, G. E., Francescutti, L. H., Predy, G., \& Cummings, G. (2006). Health promotion and disease prevention in the emergency department: A feasibility study. Canadian Journal of Emergency Medicine, 8, 100-105.

23. Fleming, M. F., Lund, M. R., Wilton, G., Landry, M., \& Scheets, D. (2008). The healthy moms study: The efficacy of brief alcohol intervention in postpartum women. Alcoholism, Clinical and Experimental Research, 32, 1600-1606.
24. Tsai, Y., Tsai, M., Lin, Y., \& Chen, E. (2009). Brief intervention for problem drinkers in a Chinese population: A randomized controlled trial in a hospital setting. Alcoholism, Clinical and Experimental Research, 33, 95-101.

25. Alwyn, T., John, B., Hodgson, R. J., \& Phillips, C. J. (2007). The addition of a psychological intervention to a home detoxification programme. Alcohol and Alcoholism, 39(6), 536-541.

26. Beckham, N. (2007). Motivational interviewing with hazardous drinkers. Journal of the American Academy of Nursing Practice, 19(2), 103-110.

27. McClellan, A. T., Kushner, H., Metzger, D., Peters, R., Smith, L., Grissom, G., et al. (1992). The fifth edition of the addiction severity index. Journal of Substance Abuse Treatment, 9, 199213.

28. Sherbourne, C. D., \& Stewart, A. L. (1991). The MOS social support survey. Social Science Medicine, 32, 705-714.

29. Radloff, L. (1977). The CES-D scale: A self-report depression scale for research in the general population. Applied Psychological Measurements, 1, 385-401.

30. Stewart, A. L., Hays, R. D., \& Ware, J. E., Jr. (1988). The MOS short-form general health survey. Reliability and validity in a patient population. Medical Care, 26, 724-735.

31. Rubenstein, L. V., Calkins, D. R., Young, R. Y., Cleary, P., Fink, A., Kosecoff, J., et al. (1989). Improving patient function: A randomized trial of functional disability screening. Annals of Internal Medicine, 111, 836-842.

32. Levensky, E. R., Forcehimes, A., O’Donohue, W. T., \& Beitz, K. (2007). Motivational Interviewing: An evidence-based approach to counseling helps patients follow treatment recommendations. The American Journal of Nursing, 107(10), 50-58.

33. Wolfers, M., de Wit, J., Hospers, H. J., Richardus, J. H., \& de Zwart, O. (2009). Effects of a short individually tailored counseling session for HIV prevention in gay and bisexual men receiving Hepatitis B vaccination. BioMed Central Public Health, 9, 1-11.

34. Nyamathi, A., Liu, Y., Marfisee, M., Shoptaw, S., Gregerson, P., Saab, S., et al. (2009). Effects of a nurse-managed program on hepatitis A and B vaccine completion among homeless adults. Nursing Research, 58(1), 13-22.

35. Nyamathi, A., Nahid, P., Berg, J., Burrage, J., Christiani, A., Aqtash, S., et al. (2008). Efficacy of nurse case-managed intervention for latent tuberculosis among homeless subsamples. Nursing Research, 57(1), 33-39.

36. Campbell, J. V., Garfein, R. S., Thiede, H., Hagan, H., Ouellet, L. J., Golub, E. T., et al. (2007). Convenience is the key to hepatitis $\mathrm{A}$ and $\mathrm{B}$ vaccination uptake among young injection drug users. Drug and Alcohol Dependence, 91S, S64-S72.

37. Linton, L. S., Peddecord, K. M., Seidman, R. L., Edwards, C., Ross, S., Gustafson, K., et al. (2003). Implementing a seventh grade vaccination law: School factors associated with completion of required immunizations. Preventive Medicine, 36, 510-517.

38. Center for Disease Control \& Prevention (2009). Surveillance for acute viral hepatitis-United States, 2007. Morbidity \& Mortality Weekly Report, 58(SS03), 1-27. http://www.cdc.gov/mmwr.

39. Lally, M. A., Montstream-Quas, S. A., Tanaka, S., Tedeschi, S. K., \& Morrow, K. M. (2008). A qualitative study among injection drug using women in Rhode Island: Attitudes toward testing, treatment, and vaccination for hepatitis and HIV. AIDS Patient Care STDs, 22(1), 53-63.

40. Kidorf, M., King, V. L., Neufeld, K., Stoller, K. B., Peirce, J., \& Brooner, R. K. (2005). Involving significant others in the care of opioid-dependent patients receiving methadone. Journal of Substance Abuse Treatment, 29, 19-27. 
41. Mehrabadi, A., Paterson, K., Pearce, M., Patel, S., Craib, K. J. P., Moniruzzaman, A., et al. (2008). Partnership for the Cedar Project. Gender differences in HIV and hepatitis $C$ related vulnerabilities among aboriginal young people who use street drugs in two Canadian cities'. Women and Health, 48(3), 235-260.

42. Fenaughty, A. M. (2003). Perceptions of power equality among drug-using women. Women and Health, 37(1), 91-107.
43. Kang, S. Y., Deren, S., \& Goldstein, M. S. (2002). Relationships between childhood abuse and neglect experience and HIV risk behaviors among methadone treatment drop-outs. Child Abuse and Neglect, 26(12), 1275-1289.

44. Grebely, J., Genoway, K., Raffa, J. D., Dhadwal, G., Rajan, T., Showler, G., et al. (2008). Barriers associated with infection among illicit drug users. Drug and Alcohol Dependence, 92, 141-147. 